\title{
Mapping of the habenulo-interpeduncular pathway in living mice using manganese-enhanced 3D MRI
}

\author{
Takashi Watanabe ${ }^{\mathrm{a}, *}$, Jelena Radulovic ${ }^{\mathrm{b}}$, Susann Boretius ${ }^{\mathrm{a}}$, Jens Frahm ${ }^{\mathrm{a}}$, Thomas Michaelis ${ }^{\mathrm{a}}$ \\ ${ }^{a}$ Biomedizinische NMR Forschungs GmbH am Max-Planck-Institut für biophysikalische Chemie, 37070 Göttingen, Germany \\ ${ }^{\mathrm{b}}$ Molekulare Neuroendokrinologie, Max-Planck-Institut für experimentelle Medizin, 37075 Göttingen, Germany \\ Received 9 August 2005; revised 27 October 2005; accepted 27 October 2005
}

\begin{abstract}
This magnetic resonance imaging (MRI) study describes mapping of the habenulo-interpeduncular pathway in living mice based on manganese-induced contrast. Six hours after intracerebroventricular microinjection of $\mathrm{MnCl}_{2}$, T1-weighted 3D MRI (2.35 T) at $117 \mu \mathrm{m}$ isotropic resolution revealed a continuous pattern of anterograde labeling from the habenula via the fasciculus retroflexus to the interpeduncular nucleus. Alternatively, the less invasive systemic administration of $\mathrm{MnCl}_{2}$ allowed for monitoring of the dynamic uptake pattern of respective neural components with even higher reproducibility across animals. Time courses covered the range from $42 \mathrm{~min}$ to $24 \mathrm{~h}$ after injection. In conclusion, manganese-enhanced MRI may open new ways for functional assessments of the habenulo-interpeduncular system in animal models with cognitive impairment.
\end{abstract}

(C) 2006 Elsevier Inc. All rights reserved.

Keywords: Habenula; Magnetic resonance imaging; Manganese; Mice; Neural pathways

\section{Introduction}

The habenular complex is a crucial relay structure for the caudally directed diencephalic conduction system. Several neuroimaging studies in humans have indicated that it is critically involved in cognition and behavior [1-3]. For example, functional magnetic resonance imaging (MRI) recently demonstrated that the habenula takes part in the reward system [4]. These findings are based on preceding animal studies that support a functional relationship between the habenula and the dopaminergic system [5-7]. In fact, various rodent models involving the habenula have been developed which resemble behavioral alterations observed in psychiatric disorders such as schizophrenia, depression and drug addiction [8-12]. Accordingly, when considering the noninvasiveness of MRI and its combination with behavioral tests in genetically modified animals, a suitable MRI technique for investigations of active habenular neurons in behaving mice turns out to be highly desirable.

Recent advances in neuroimaging of animals offer $\mathrm{MnCl}_{2}$ as an MRI contrast agent for functional assessments

* Corresponding author. Fax: +49 5512011307.

E-mail address: twatana@gwdg.de (T. Watanabe). of rodent brain [13-18]. Depending on the neuronal uptake of paramagnetic $\mathrm{Mn}^{2+}$ ions through calcium channels and their subsequent axonal transport, T1-weighted MRI allows for a mapping of active neural pathways at high spatial resolution and without the susceptibility artifacts often encountered in deoxyhemoglobin-based functional MRI.

The purpose of this work was to develop corresponding approaches for mapping the habenular complex in living mice by using T1-weighted 3D MRI at isotropic spatial resolution after either intracerebroventricular microinjection or systemic administration of $\mathrm{MnCl}_{2}$.

\section{Materials and methods}

\subsection{Intracerebroventricular $\mathrm{Mn}^{2+}$ microinjection}

Seven male mice (animals 1-7: C57BL/6J, 9-12 weeks old, 24-28 g) were obtained from Centre d'Elevage Janvier (Le Genest St. Isle, France). The animals were individually housed under conventional conditions in macrolon cages according to the recommendations of the Society for Laboratory Animal Science (Germany). Experiments were performed in accordance with the European Council Directive (86/609/EEC) and with permission of the animal 
protection law enforced by the District Government of Braunschweig, State of Lower Saxony.

The bregma, the sagittal suture and the surface of the skull were used as references for the anterior-posterior (AP), lateral (L) and ventral (V) coordinates, respectively. For the implantation of the cannula, avertin (1.2\%) was injected intraperitoneally (ip, $0.02 \mathrm{ml} / \mathrm{g} \mathrm{bw}$ ). A set of two guide cannulae (26-gauge, C235, Plastics One, Roanoke, VA) was placed into the lateral ventricles $(A P=0 \mathrm{~mm}$, $\mathrm{L}= \pm 1.0 \mathrm{~mm}$ and $\mathrm{V}=3.0 \mathrm{~mm}$ ) in accordance with stereotaxic plates [19]. The cannulae were fixed to the skull by dental cement.

Intraventricular injections of $\mathrm{MnCl}_{2}(0.25 \mu \mathrm{l})$ were performed 4-5 days after the cannula surgery using only the left-hemispheric cannula. $\mathrm{MnCl}_{2}$ (Sigma, Taufkirchen, Germany) was dissolved in sterile artificial cerebrospinal fluid (CSF) on the day of injection and prepared in three different concentrations (5 mM: animals $1-3 ; 20 \mathrm{mM}$ : animals 4-6; $50 \mathrm{mM}$ : animal 7). The artificial CSF contained $\mathrm{NaCl}(130 \mathrm{mM}), \mathrm{NaHCO}_{3}(24 \mathrm{mM}), \mathrm{MgSO}_{4}$ (1.5 mM), $\mathrm{CaCl}_{2}(2 \mathrm{mM}), \mathrm{KCl}$ (3.5 mM), $\mathrm{NaH}_{2} \mathrm{PO}_{4}(1.25$ $\mathrm{mM})$ and glucose $(10 \mathrm{mM})$ adjusted to $\mathrm{pH} 7.4$ and 300 $\mathrm{mOsm} / \mathrm{kg} \mathrm{H}_{2} \mathrm{O}$. The manganese concentrations were chosen to be well below acute toxic levels and sufficiently high to ensure proper MRI contrast. For example, in rats intracerebral injections of $1 \mu \mathrm{l}$ of $500 \mathrm{mM} \mathrm{MnCl} \mathrm{m}_{2}$ were shown to be without change, whereas a concentration of $1000 \mathrm{mM}$ $\mathrm{MnCl}_{2}$ caused a significant reduction of neurochemical markers such as GABA [20]. On the other hand, previous MRI studies of the hippocampal system of mice were successfully carried out using a dose as low as $0.25 \mu \mathrm{l}$ of 5 $\mathrm{mM} \mathrm{MnCl}_{2}$ [21].

Animals were exposed to an isoflurane anesthesia (Abbott, Wiesbaden, Germany) and placed in a prone position. The $\mathrm{MnCl}_{2}$ injection was performed with the use of a 28-gauge cannula connected via plastic tubing to a Hamilton microsyringe. The solution $(0.25 \mu \mathrm{l})$ was administered into the left lateral ventricle by a microinjector (CMA/Microdialysis) over a 15 -s period. Afterwards, avertin (ip, $1.2 \%, 0.02 \mathrm{ml} / \mathrm{g} \mathrm{bw}$ ) was injected to minimize possible stress during transportation to the MRI facility. Magnetic resonance imaging examinations were performed at $2 \mathrm{~h}$ (animals 4 and 7), $6 \mathrm{~h}$ (animals 1-6) and $24 \mathrm{~h}$ (animals 4 and 5) after $\mathrm{MnCl}_{2}$ administration. For the first MRI measurement, the implanted cannulae were removed. The incisions of the scalp were covered with lidocaine hydrochloride ( $2 \%$ xylocaine gel). After each anesthesia, the animals were recovered and became normally active with free access to food and water.

\subsection{Systemic $\mathrm{Mn}^{2+}$ administration}

Six female mice (animals 8-13, NMRI, 7 weeks old, 28-34 g) received $\mathrm{MnCl}_{2}$ dissolved in distilled water (120 $\mathrm{mM}, 5 \mathrm{ml} / \mathrm{kg} \mathrm{bw}$ ) via subcutaneous injections. The solution was administered into the axillary adipose tissue bilaterally. In general, it has been reported that about $0.4 \%$ of the subcutaneously administered $\mathrm{Mn}^{2+}$ enters the brain [22]. In comparison to intraperitoneal and intravenous injections, subcutaneous injections lead to a slower uptake of $\mathrm{Mn}^{2+}$ into the systemic circulation and therefore minimize acute effects on the cardiovascular system such as hypotension.

In a first group of animals (8-10) MRI examinations were performed before as well as 2, 6 and $24 \mathrm{~h}$ after $\mathrm{Mn}^{2+}$ administration. More detailed uptake kinetics were studied in a second group of animals (11-13) before as well as 42, 132, 222, 312 and $402 \mathrm{~min}$ after $\mathrm{Mn}^{2+}$ administration. The time points correspond to the midpoints of respective $3 \mathrm{D}$ MRI acquisitions (see below). Whereas animals 8 to 10 were recovered from anesthesia between each measurements, animals 11 to 13 were kept under anesthesia within the magnet. All other procedures were as described above.

\subsection{Magnetic resonance imaging}

For MRI, anesthesia was induced by intraperitoneal injection of xylazine (14 mg/kg bw) and ketamine $(90 \mathrm{mg} /$ $\mathrm{kg} \mathrm{bw})$. The animals were intubated with a purpose-built polyethylene endotracheal tube $(0.58 \mathrm{~mm}$ inner diameter, $0.96 \mathrm{~mm}$ outer diameter) and artificially ventilated using a respirator (TSE, Bad Homberg, Germany) with an inspiratory time of $0.18 \mathrm{~s}$, a respiratory rate of 80 breaths per minute and an estimated tidal volume of $0.15-0.25 \mathrm{ml}$. Anesthesia was maintained using $0.2-0.6 \%$ halothane in a 7:3 mixture of $\mathrm{N}_{2} \mathrm{O}$ and $\mathrm{O}_{2}$. As demonstrated in Fig. 1, the animals were placed in a prone position with their head fixed on a purpose-built head holder. Heated water was used to maintain rectal body temperature at $37 \pm 1{ }^{\circ} \mathrm{C}$.

MRI measurements were carried out at $2.35 \mathrm{~T}$ using a MRBR 4.7/400-mm magnet (Magnex Scientific, Abing-

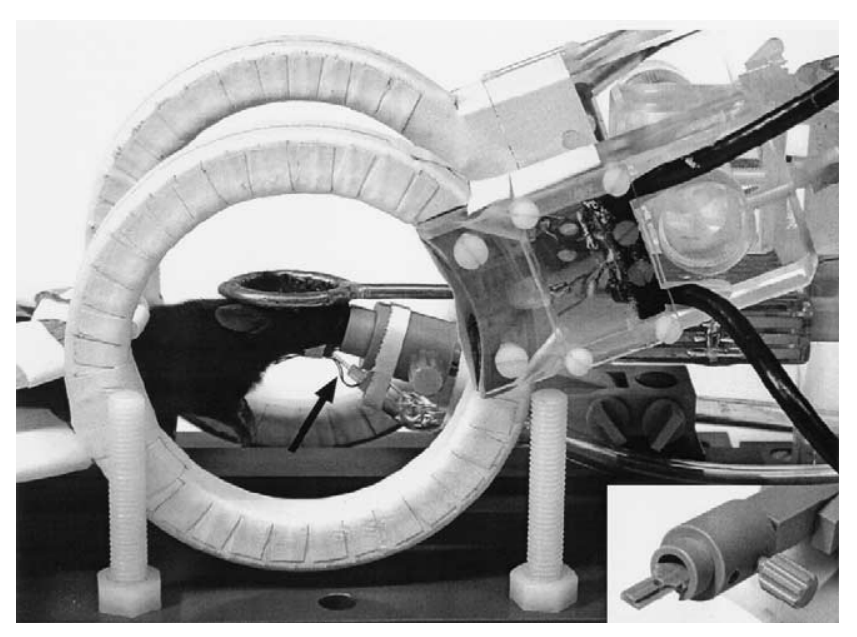

Fig. 1. Experimental setup for high-resolution 3D MRI of mouse brain in vivo. Radiofrequency excitation and signal reception were accomplished with the use of a Helmholtz coil $(100 \mathrm{~mm})$ and an elliptical surface coil (20 $\mathrm{mm}$ AP, $12 \mathrm{~mm}$ left-right), respectively. The arrow denotes the endotracheal tube. The insert depicts the head holder comprising a nose cone and bite bar. 
don, UK) equipped with B-GA20 gradients $(200 \mathrm{~mm}$ inner diameter, $100 \mathrm{mT} / \mathrm{m}$ maximum strength) and driven by a DBX system (Bruker Biospin, Ettlingen, Germany). Radiofrequency excitation and signal reception were accomplished with the use of a Helmholtz coil (100 $\mathrm{mm}$ inner diameter) and an elliptical surface coil $(20 \mathrm{~mm}$ AP, $12 \mathrm{~mm}$ left-right), respectively. High-resolution 3D MRI data sets were acquired using a T1-weighted gradient-echo MRI sequence (rf-spoiled 3D FLASH, TR/ $\mathrm{TE}=17 / 7.6 \mathrm{~ms}$, flip angle $25^{\circ}, 32$ averages) optimized for studies of mouse brain at $117 \mu \mathrm{m}$ isotropic voxel resolution [23]. The total measuring time for a 3D MRI scan was $84 \mathrm{~min}$.
In accordance with resolved anatomic structures, quantitative evaluations were based on cross sections obtained by multiplanar reconstructions from the original 3D MRI data sets using software supplied by the manufacturer (ParaVision, Bruker). Following a strategy outlined by Watanabe et al. [24], the signal-to-noise ratio (SNR), here defined as the mean MRI signal intensity divided by the standard deviation of the noise, was determined in standardized regions of interest within enhanced structures. To calculate percent changes of the SNR after $\mathrm{Mn}^{2+}$ enhancement for selected regions within the habenulo-interpeduncular pathway (animals 11-13), values were individually normalized to the SNR obtained before injection.
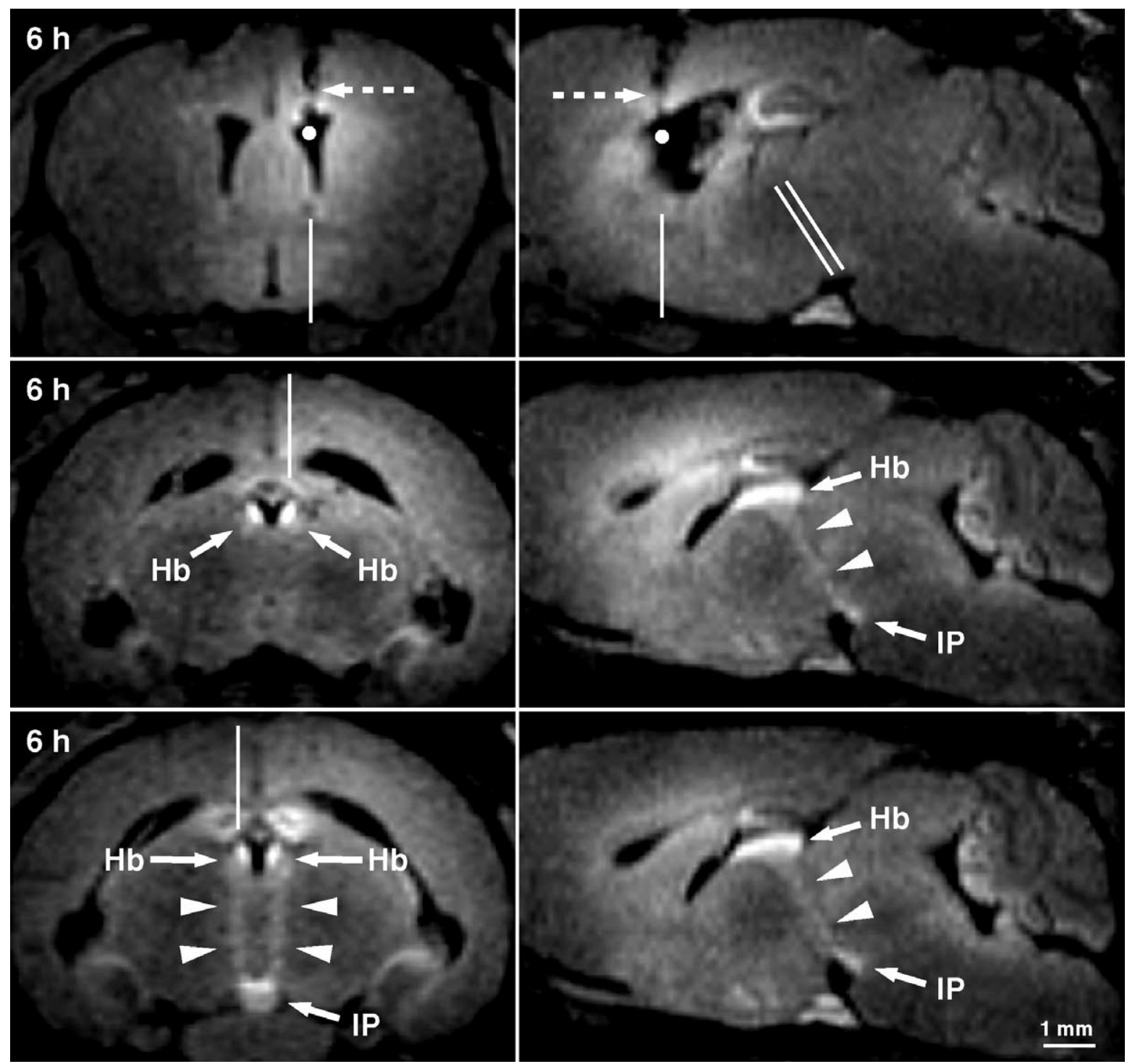

Fig. 2. $\mathrm{Mn}^{2+}$-enhanced MRI of the brain of a mouse $6 \mathrm{~h}$ after injection of $\mathrm{MnCl}_{2}$ (animal 1, $0.25 \mu \mathrm{l}, 5 \mathrm{mM}$ ) into the left lateral ventricle. (Top) The lefthemispheric injection site (white dots) is depicted in (left) a coronal and (right) a parasagittal section $0.8 \mathrm{~mm}$ lateral to the midline. Dashed arrows denote the needle tract. Solid vertical lines refer to respective section orientations, while oblique lines indicate the positions of the coronal sections shown below. (Middle) The anterior parts of the habenulae ( $\mathrm{Hb}$ ) are shown in (left) a coronal oblique section together with (right) the connection (arrowheads) between the left habenula and interpeduncular nucleus (IP). As indicated by a vertical line, the parasagittal section is $0.35 \mathrm{~mm}$ lateral to the midline. (Bottom) The fasciculus retroflexus of both sides (arrowheads) is shown in (left) a coronal oblique section, while (right) the right fasciculus retroflexus is delineated in a parasagittal section $0.35 \mathrm{~mm}$ lateral to the midline. 


\section{Results and discussion}

\subsection{Intracerebroventricular $\mathrm{Mn}^{2+}$ microinjection}

Fig. 2 demonstrates that the uptake of $\mathrm{Mn}^{2+}$ from the CSF into brain tissue results in a clear delineation of the habenulae $6 \mathrm{~h}$ after a microinjection of $\mathrm{MnCl}_{2}$ into the left lateral ventricle. In terms of soft-tissue contrast, optimal enhancement was achieved after intracerebroventricular injection of $5 \mathrm{mM} \mathrm{MnCl} 2$. Magnetic resonance imaging signal increases are seen in tissue adjacent to the ventricular

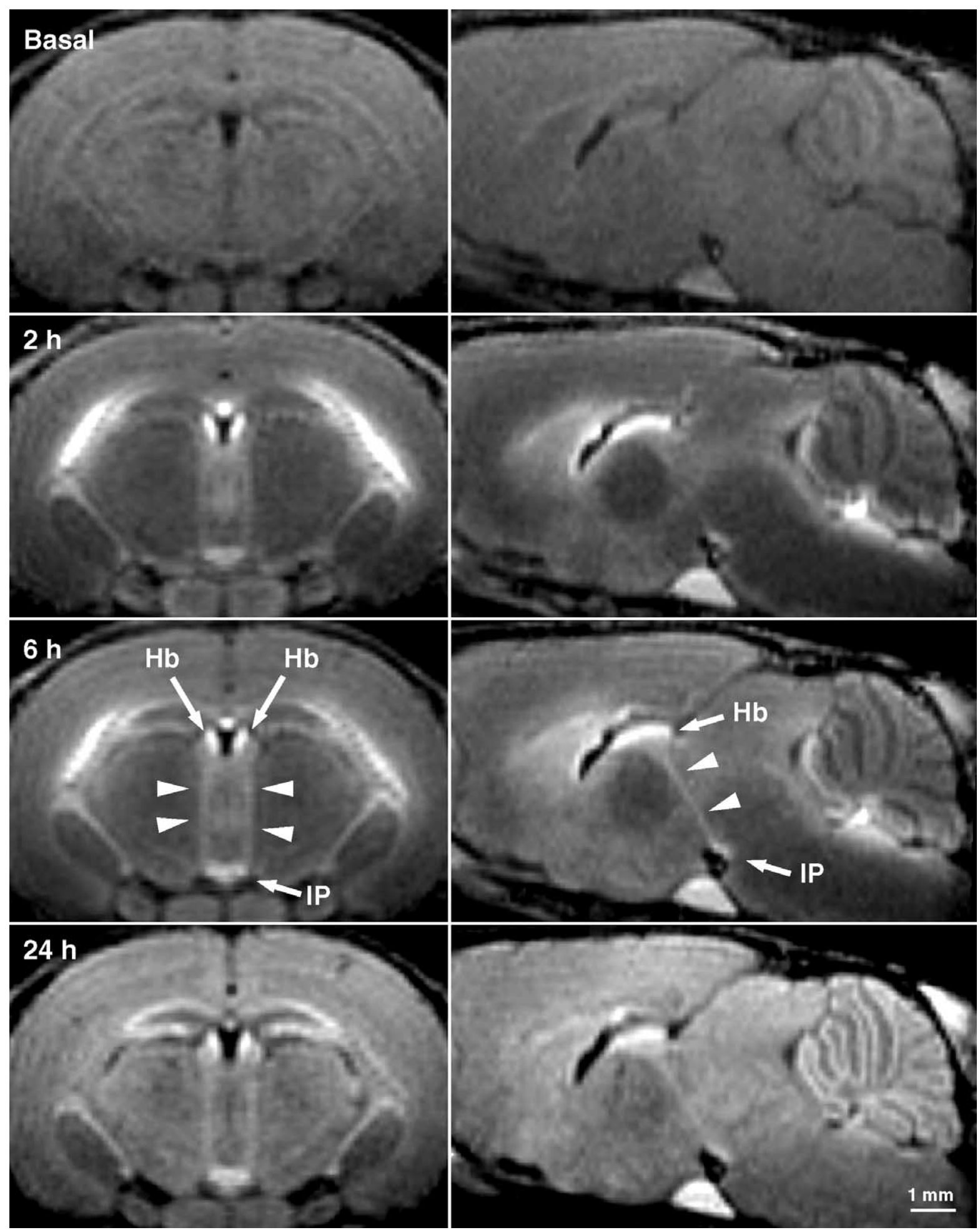

Fig. 3. $\mathrm{Mn}^{2+}$-enhanced MRI of the brain of a mouse before as well as 2, 6 and $24 \mathrm{~h}$ after subcutaneous injection of $\mathrm{MnCl}_{2}(\mathrm{animal} 8,120 \mathrm{mM}, 5 \mathrm{ml} / \mathrm{kg}$ bw). (Left) A coronal and (right) right-hemispheric parasagittal section $0.4 \mathrm{~mm}$ lateral to the midline show enhanced structures along the habenulo-interpeduncular pathway (arrowheads). Section orientations and anatomic labeling as in Fig. 2. 
Table 1

Signal-to-noise ratio of enhanced structures after subcutaneous $\mathrm{MnCl}_{2}$

\begin{tabular}{llllll}
\hline Region & $\begin{array}{c}\text { Area/ } \\
\mathrm{mm}^{2}\end{array}$ & Basal & $2 \mathrm{~h}$ & $6 \mathrm{~h}$ & $24 \mathrm{~h}$ \\
\hline $\begin{array}{c}\text { Habenular } \\
\text { nuclei }\end{array}$ & 0.08 & $28.9 \pm 2.3$ & $68.0 \pm 4.4$ & $71.2 \pm 1.6$ & $59.5 \pm 2.8$ \\
$\begin{array}{c}\text { Fasciculus } \\
\text { retroflexus }\end{array}$ & 0.40 & $25.9 \pm 2.4$ & $35.1 \pm 3.5$ & $41.5 \pm 0.7$ & $41.2 \pm 3.3$ \\
$\begin{array}{c}\text { Interpeduncular } \\
\text { nucleus }\end{array}$ & 0.53 & $23.4 \pm 2.9$ & $43.2 \pm 7.1$ & $52.3 \pm 1.6$ & $47.1 \pm 3.5$ \\
& & & & &
\end{tabular}

The data represent mean values \pm S.D. averaged across hemispheres and animals $(n=3$, animals $8-10)$.

spaces including the lower brainstem and cerebellum. These findings indicate that $\mathrm{Mn}^{2+}$ ions become distributed by CSF flow from the lateral ventricle to the third and fourth ventricle. Accordingly, adjacent brain tissue must be expected to be well exposed to $\mathrm{Mn}^{2+}$. Among respective neural components, the most pronounced enhancement was seen in both the left and right habenula. From the habenulae, enhanced fiber bundles (arrowheads in Fig. 2) can be tracked bilaterally across the thalamus to the interpeduncular nucleus in the midbrain. In accordance with anterograde tracing studies of habenular neurons using intracellular tracers [25], this connection represents the fasciculus retroflexus. Its enhancement unequivocally confirms the uptake and subsequent axonal transport of $\mathrm{Mn}^{2+}$ by habenular neurons. No differences were observed for the connections ipsilateral or contralateral to the injection site.

Because the habenula is located beneath the lateral wall of the third ventricle, CSF flow can be exploited to efficiently deliver $\mathrm{Mn}^{2+}$ to this neuronal assembly with the use of a surgical intervention far away from the target structure. In contrast, direct intraparenchymal injections [21] seem inappropriate in view of the small size of the mouse habenula $(<0.8 \mathrm{~mm}$ in height and width) and the risk of tissue damage due to needle insertion and subsequent infusion. On the other hand, it should be noted that the clear pattern of enhancement found for animal 1 (Fig. 2) was not achieved in animals 2 and 3 studied with the same $\mathrm{Mn}^{2+}$ concentration. In quantitative terms, the SNR of $38.4 \pm 12.8$ $(n=3)$ obtained for the enhanced habenulae reveals an insufficient reproducibility as indicated by the large standard deviation. The situation was not improved by using higher $\mathrm{MnCl}_{2}$ concentrations. For example, in animals 4 to 6 the use of $20 \mathrm{mM} \mathrm{MnCl} 2$ did not lead to a reproducible enhancement of the habenula. On the other hand, although the application of $50 \mathrm{mM} \mathrm{MnCl} 2$ in animal 7 resulted in a robust MRI signal increase in the habenula, the $\mathrm{Mn}^{2+}$ contrast was compromised by strong unspecific effects in tissues adjacent to ventricular spaces.

The observed interindividual variability most likely results from differences in the $\mathrm{Mn}^{2+}$ content within the CSF rather than from functional response variances of individual animals. A major reason may be due to the fact that under in vivo conditions - and in contrast to what might be assumed from histologic sections — the choroid plexus occupies considerable space in the lateral ventricles. Thus, despite the use of C57BL/6J mice which are known for larger ventricular spaces than other strains $[23,26]$, it appeared beyond the investigator's control to position the tip of the injection needle exclusively within the narrow CSF space without contact to the choroid plexus. The uptake of $\mathrm{Mn}^{2+}$ into the choroid plexus may therefore cause variable concentrations in the CSF (and adjacent brain tissue) of different animals and generally hamper the applicability of the intracerebroventricular approach for functional assessments of habenular neurons.

\subsection{Systemic $\mathrm{Mn}^{2+}$ administration}

As shown in Fig. 3 for 3D MRI acquisitions at different times after systemic $\mathrm{Mn}^{2+}$ administration (animals 8-10), the use of a high-dose subcutaneous injection of $\mathrm{MnCl}_{2}$ unraveled the entire neural pathway from the habenular complex via the fasciculus retroflexus to the interpeduncular nuclei bilaterally. The concurrent enhancement of the habenula and fasciculus retroflexus further supports the neuronal uptake of $\mathrm{Mn}^{2+}$ after systemic administration and extends preliminary observations using low-dose administrations of $\mathrm{MnCl}_{2}$ [18].

Table 1 summarizes SNR values obtained for the habenula, fasciculus retroflexus and interpeduncular nucleus as a function of time after systemic administration. Best results in terms of soft-tissue contrast of the entire pathway were achieved $6 \mathrm{~h}$ after injection. At $24 \mathrm{~h}$ after injection the soft-tissue contrast faded. However, in agreement with previous studies [24], such long exposure times lead to the enhancement of brain structures such as hippocampal formation and cerebellum (bottom left and right of Fig. 3, respectively).

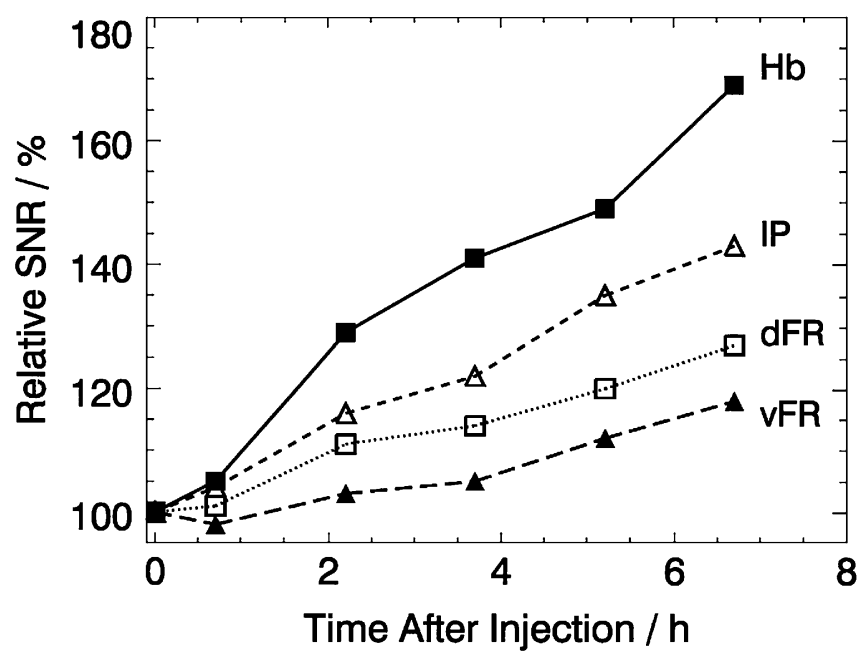

Fig. 4. Time courses of relative SNR (mean values \pm S.E.M. averaged across animals 11-13) within the habenulo-interpeduncular pathway after systemic $\mathrm{MnCl}_{2}$ administration. The enhancement in the dorsal half of the fasciculus retroflexus (dFR) close to the habenula $(\mathrm{Hb})$ precedes the $\mathrm{Mn}^{2+}$ accumulation in the ventral half of the fasciculus retroflexus (vFR) closer to the IP. 
Fig. 4 shows time courses of the mean SNR within selected regions of the habenulo-interpeduncular pathway (animals 11-13). At 132 min after injection, the habenula reveals an SNR increase as large as $30 \%$, whereas in the interpeduncular nucleus such a pronounced enhancement was not seen until $312 \mathrm{~min}$ after injection. Most importantly, the graph demonstrates the $\mathrm{Mn}^{2+}$-induced SNR increase in the dorsal part of the fasciculus retroflexus (11\% at $132 \mathrm{~min}$ postinjection) to precede the enhancement in the ventral part of the tract which reaches similar values not until $312 \mathrm{~min}$ after the injection. Together with the marked $\mathrm{Mn}^{2+}$ accumulation observed in the habenula, the delayed enhancement in the ventral part of the fasciculus retroflexus clearly indicates that the anterograde axonal transport by habenular neurons contributes to the $\mathrm{Mn}^{2+}$ accumulation in this tract. The graph also reveals conditions of unsaturated $\mathrm{Mn}^{2+}$ accumulation in this projection pathway for at least 6 $\mathrm{h}$ after administration. Accordingly, this period may be exploited for functional assessments of specific neuronal populations as demonstrated in the song system of living canaries [27].

It has been suggested that the choroid plexus becomes the predominant route for $\mathrm{Mn}^{2+}$ uptake into the central nervous system at increased plasma concentration [28]. Thus, together with the findings for intracerebroventricular injections, significant amounts of $\mathrm{Mn}^{2+}$ should be deliverable to the habenula via ventricular CSF flow after systemic administration of a high dose of $\mathrm{MnCl}_{2}$. The procedure not only avoids a surgical intervention, but also leads to a considerably better interindividual reproducibility of enhancement patterns than intracerebroventricular microinjections. The observation of similar findings in all animals studied is quantitatively supported by the small standard deviation values reported in Table 1.

Hyperactivity of the habenulo-interpeduncular pathway has been hypothesized to be involved in reduced dopamine activity and thus reward-related behaviors [7]. So far, a functional characterization of the habenula in a genetic animal model with altered behavior has been accomplished using postmortem methods such as cytochrome oxidase histochemistry [11]. The method presented here combines several advantages: (i) MRI is inherently noninvasive and the exogenous contrast requires only a single subcutaneous injection, (ii) the information is of a true $3 \mathrm{D}$ nature and available for retrospective reconstructions of arbitrary sections or surfaces and (iii) the approach may be applied repeatedly during multiple follow-up studies and combined with behavioral tests in individual animals. Together, dynamic $\mathrm{Mn}^{2+}$-enhanced MRI is expected to become a complementary neuroimaging technique for in vivo studies of habenular neurons.

\section{Conclusions}

The results suggest that $\mathrm{Mn}^{2+}$-enhanced MRI may be used for structural and functional assessments of mouse models involving disturbances of the descending diencephalic system. An intracerebroventricular route can be chosen to highlight the entire habenulo-interpeduncular pathway using a single dose of only $0.25 \mu 1$ of $5 \mathrm{mM} \mathrm{MnCl}_{2}$. Systemic $\mathrm{Mn}^{2+}$ administration offers a robust and even less invasive alternative for a quantifiable evaluation of the habenulointerpeduncular system. This strategy is currently applied for a characterization of synaptic activity in knockout mouse models of schizophrenia-related genes.

\section{References}

[1] Sandyk R. Pineal and habenula calcification in schizophrenia. Int J Neurosci 1992;67:19-30.

[2] Caputo A, Ghiringhelli L, Dieci M, Giobbio GM, Tenconi F, Ferrari L, et al. Epithalamus calcifications in schizophrenia. Eur Arch Psychiatry Clin Neurosci 1998;248:272-6.

[3] Morris JS, Smith KA, Cowen PJ, Friston KJ, Dolan RJ. Covariation of activity in habenula and dorsal Raphé nuclei following tryptophan depletion. NeuroImage 1999;10:163-72.

[4] Ullsperger M, von Cramon DY. Error monitoring using external feedback: specific roles of the habenular complex, the reward system, and the cingulate motor area revealed by functional magnetic resonance imaging. J Neurosci 2003;23:4308-14.

[5] Lisoprawski A, Herve D, Blanc G, Glowinski J, Tassin JP. Selective activation of the mesocortico-frontal dopaminergic neurons induced by lesion of the habenula in the rat. Brain Res 1980;183:229-34.

[6] Nishikawa T, Fage D, Scatton B. Evidence for, and nature of, the tonic inhibitory influence of the habenulointerpeduncular pathway upon cerebral dopaminergic transmission in the rat. Brain Res 1986;373: $324-36$.

[7] Shumake J, Gonzalez-Lima F. Brain systems underlying susceptibility to helplessness and depression. Behav Cogn Neurosci Rev 2003;2:198-221.

[8] Ellison G. Stimulant-induced psychosis, the dopamine theory of schizophrenia, and the habenula. Brain Res Rev 1994;19:223-39.

[9] Ellison G. Neural degeneration following chronic stimulant abuse reveals a weak link in brain fasciculus retroflexus, implying the loss of forebrain control circuitry. Eur Neuropsychopharmacol 2002;12: 287-97.

[10] Caldecott-Hazard S, Mazziotta J, Phelps M. Cerebral correlates of depressed behavior in rats, visualized using 14C-2-deoxyglucose autoradiography. J Neurosci 1988;8:1951-61.

[11] Shumake J, Edwards E, Gonzalez-Lima F. Opposite metabolic changes in the habenula and ventral tegmental area of a genetic model of helpless behavior. Brain Res 2003;963:274-81.

[12] Lecoutier L, Neijt HC, Kelly PH. Habenula lesions cause impaired cognitive performance in rats: implications for schizophrenia. Eur $\mathrm{J}$ Neurosci 2004;19:2551-60.

[13] Lin YJ, Koretsky AP. Manganese ion enhances T1-weighted MRI during brain activation: an approach to direct imaging of brain function. Magn Reson Med 1997;38:378-88.

[14] Pautler RG, Silva AC, Koretsky AP. In vivo neuronal tract tracing using manganese-enhanced magnetic resonance imaging. Magn Reson Med 1998;40:740-8.

[15] Koretsky AP, Silva AC. Manganese-enhanced magnetic resonance imaging (MEMRI). NMR Biomed 2004;17:527-31.

[16] Silva AC, Lee JH, Aoki I, Koretsky AP. Manganese-enhanced magnetic resonance imaging (MEMRI): methodological and practical considerations. NMR Biomed 2004;17:532-43.

[17] van der Linden A, van Meir V, Tindemans I, Verhoye M, Balthazart J. Applications of manganese-enhanced magnetic resonance imaging (MEMRI) to image brain plasticity in song birds. NMR Biomed 2004; $17: 602-12$. 
[18] Watanabe T, Frahm J, Michaelis T. Functional mapping of neural pathways in rodent brain in vivo using manganese-enhanced threedimensional MRI. NMR Biomed 2004;17:554-68.

[19] Franklin KBJ, Paxinos G. The mouse brain in stereotaxic coordinates. San Diego: Academic Press; 1997.

[20] Brouillet EP, Shinonu L, McGarvey U, Hochberg F, Beal MF. Manganese injection into the rat striatum produces excitotoxic lesions by impairing energy metabolism. Exp Neurol 1993;120:89-94.

[21] Watanabe T, Radulovic J, Spiess J, Natt O, Boretius S, Frahm J, et al. In vivo 3D MRI staining of the mouse hippocampal system using intracerebral injection of $\mathrm{MnCl}_{2}$. NeuroImage 2004;22:860-7.

[22] Gianutsos G, Seltzer MD, Saymeh R, Wang Wu ML, Michel RG. Brain manganese accumulation following systemic administration of different forms. Arch Toxicol 1985;57:272-5.

[23] Natt O, Watanabe T, Boretius S, Radulovic J, Frahm J, Michaelis T. High-resolution 3D MRI of mouse brain reveals small cerebral structures in vivo. J Neurosci Methods 2002;120:203-9.
[24] Watanabe T, Natt O, Boretius S, Frahm J, Michaelis T. In vivo 3D MRI staining of mouse brain after subcutaneous application of $\mathrm{MnCl}_{2}$. Magn Reson Med 2002;48:852-9.

[25] Herkenham M, Nauta WJ. Efferent connections of the habenular nuclei in the rat. J Comp Neurol 1979;187:19-48.

[26] Schwarcz A, Natt O, Watanabe T, Boretius S, Frahm J, Michaelis T. Localized proton MRS of cerebral metabolite profiles in different mouse strains. Magn Reson Med 2003;48:822-7.

[27] Tindemans I, Verhoye M, Balthazart J, van der Linden A. In vivo dynamic ME-MRI reveals differential functional responses of RAand area X-projecting neurons in the HVC of canaries exposed to conspecific song. Eur J Neurosci 2003;18:3352-60.

[28] Aschner M. Manganese homeostasis in the CNS. Environ Res A 1999;80:105-9. 